\title{
O encarceramento em massa em São Paulo
}

\author{
Jacqueline Sinhoretto, Giane Silvestre e \\ Felipe Athayde Lins de Melo
}

Introdução

A população prisional no estado de São Paulo vem crescendo acentuadamente nos últimos quinze anos. Se em 1992 existiam 30670 pessoas presas distribuídas em 43 estabelecimentos penitenciários (cf. Salla, 2007), atualmente são mais de 190 mil, o que corresponde a mais de $30 \%$ do total de presos do país, distribuídos em 154 unidades prisionais, além dos dezesseis complexos ainda em construção (cf. Depen, 2012). A grande maioria desses estabelecimentos encontra-se em pequenas cidades paulistas; ao todo são 104 unidades espalhadas pelo interior do estado. $\mathrm{O}$ acelerado crescimento do sistema prisional é caracterizado, portanto, por uma política de descentralização das unidades e de encarceramento em massa ${ }^{1}$, posto que focalizado em acusados por crimes patrimoniais e drogas, jovens, homens e oriundos das periferias urbanas.

Este artigo baseia-se em trabalhos de observação participante e entrevistas com atores significativos do cotidiano prisional. São abordados dois aspectos que envolvem a expansão e a gestão do sistema penitenciário, a saber: as transformaçóes e os conflitos sociais nas dinâmicas urbanas das pequenas cidades que receberam unidades penitenciárias e a gestão de presos, que ocorre de forma peculiar, sendo compartilhada entre a administração e os internos. Tal compartilhamento se dá num plano geral das relaçôes, que vai desde o

1. Para uma discussão mais completa sobre interiorização penitenciária, ver Silvestre (2012); Melo (2012); Godoi (2011); Biondi (2010); Dias e Silvestre (2009). 
2. Trata-se de uma concepção normativa que propốe a realização de diversas açōes compreendidas como de "reintegração social" da populaçăo prisional.

3. Segundo os dados do Departamento Penitenciário Nacional, referentes a junho de 2012 , enquanto a taxa nacional de encarceramento é de 288 presos por 100 mil habitantes, no estado de São Paulo esse número sobe para 462. Disponível em $<$ http://portal.mj.gov.br/main. asp? View $=\% 7$ в $574 \mathrm{E} 9 \mathrm{CE}-$ 3C7D-437A-A5B6-22166AD 2E $896 \% 7 \mathrm{D} \&$ Team $=$ \&para $\mathrm{ms}=$ itemID $=\% 7 \mathrm{BC} 37 \mathrm{~B} 2 \mathrm{AE} 9$ 4C68-4006-8B16-24D28407 509C\%7D;\&UipartUiD $=\% 7 \mathrm{~B}$ 2868BA3C-1C72-4347-BE11-A26F70F4Св26\%7D>, consultado em 26/2/2013. controle dos conflitos entre moradores, familiares de presos e autoridades municipais até as ações de "tratamento penitenciário"2, como é o caso da política educacional. Os presos que são monitores de educação configuram um grupo diferenciado, que negocia constantemente a execução de seu trabalho tanto com a administração quanto com a organização dos presos.

Ao mesmo tempo, o trânsito constante de presos e familiares pelas unidades prisionais e bairros populares propiciou a difusão dos códigos de conduta por esses espaços. As conclusões obtidas nos trabalhos aqui discutidos apontam para o reconhecimento de novas personagens nas dinâmicas prisionais. Novas personagens que acabam por se responsabilizar por tarefas de "tratamento penitenciário" delegadas formal ou informalmente, assumindo também o desempenho das normas e moralidades que hoje regem a vida nas prisões.

Do ponto de vista analítico, o texto discute teses, divulgadas por estudos recentes, que se contrapõem: de um lado, a defesa da existência de uma coerência entre as políticas e os dispositivos do endurecimento penal, do tratamento e da repressão crescente, que resultaria na neutralização da garantia de direitos aos presos, recorrendo a táticas ilegais e de exceção; de outro, estudos que identificam o surgimento dos coletivos de presos como a emergência de um novo sujeito político que muda a correlação de forças na gestão cotidiana da repressão, da vigilância, da disciplina e da violência no interior das prisões e nos espaços sociais em que seus efeitos são sentidos.

Diante dessas teses, a análise aqui proposta busca interpretar as dinâmicas da punição no contexto contemporâneo como efeitos de uma tensão entre esses vetores opostos, porém complementares no interior do campo de forças, quais sejam: o controle social repressivo centralizado, que endurece os dispositivos legais, e o controle social difuso baseado em dispositivos de segurança e compartilhados entre múltiplos agentes envolvidos no cotidiano penitenciário que intervêm sobre o espaço-tempo prisional, reforçado pelas lutas de emergência do novo sujeito político, os coletivos de presos.

\section{Encarceramento em massa e gestão compartilhada}

Os dados sobre o número de unidades prisionais e pessoas presas em São Paulo evidenciam o que chamamos de encarceramento em massa. Tal caráter do crescimento no número de prisões neste estado destoa muito até mesmo do padrão brasileiro ${ }^{3}$. Se o país é considerado internacionalmente o quarto maior em número de presos por habitantes, a média paulista tem sido supe- 
rior à do país há pelo menos duas décadas. Quando David Garland (2008) conceituou o fenômeno do encarceramento em massa, chamou a atenção para a focalização sobre grupos sociais específicos, tal como ocorre em São Paulo com a população jovem, negra e residente nos bairros de periferia. Se os números não forem por si sós eloquentes, pesquisas de caráter qualitativo têm demonstrado o impacto do encarceramento sobre a dinâmica da vida familiar e das relações sociais em etnografias realizadas nos bairros populares. Vera Telles (2007) percebeu em campo essas mudanças ao observar que se tornou comum entre as famílias pobres de determinados bairros ter parentes e conhecidos presos. Relatou inclusive as mudanças no cotidiano das vizinhanças em ocasiōes em que os jovens que cumprem pena retornam para usufruir dos indultos temporários em seus locais de origem. Nas cidades que sediam as penitenciárias, os efeitos do encarceramento também são sentidos de modo significativo no cotidiano do comércio, do trabalho, da vida moral local e das famílias.

Propomo-nos a discutir neste artigo as consequências desse encarceramento, sobretudo no que tange à administração dos conflitos e o compartilhamento da gestão prisional, que excede os muros das prisões. São mais de cem unidades prisionais distribuídas pelo interior de São Paulo, em pequenas e médias cidades, que acabam por vivenciar os efeitos não planejados da instalação de uma prisão. Efeitos que vão desde problemas estruturais, como uma repentina sobrecarga da rede de esgoto da cidade, até o aumento da sensação de insegurança da população, muito alimentado pelas representaçôes dos "criminosos" que ali estão presos.

Nesse contexto, a presença das prisões afeta a vida local dessas cidades, impactando em setores como a assistência social, a saúde, a segurança etc., gerando ainda tensóes que excedem a capacidade local de gerenciar os conflitos. Além dessa dimensão conflitiva, é possível observar o compartilhamento da gestão do cotidiano prisional, constantemente negociada fora dos muros das prisóes.

Os dados empíricos coletados na cidade de Itirapina, interior de São Paulo, onde duas penitenciárias impactam a vida de aproximadamente 15 mil habitantes, demonstram que os conflitos decorrentes da convivência entre moradores e familiares de presos são de pelo menos duas ordens: materiais e morais. Tais conflitos são administrados em diversos espaços públicos e de participação coletiva, como o Conselho Comunitário de Segurança (Conseg), e algumas decisões sobre o cotidiano das prisões são negociadas entre autoridades municipais e administração prisional. 
Para efeito explicativo, pode-se afirmar que os conflitos de ordem material são explicitados pelo aumento na demanda de atendimentos na saúde pública local, nos serviços prestados pela assistência social e pela falta de efetivo e viaturas policiais para o policiamento do município - já que ambos ficam à disposição das penitenciárias para a escolta das transferências e deslocamentos dos presos. Os relatos obtidos em entrevistas com moradores, policiais e agentes penitenciários de Itirapina demonstram esses fatos e os conflitos decorrentes:

O que causa problema para o nosso município, para o hospital, o que causa um grande problema para o serviço social do município e o que causa um grande problema de segurança pública, tanto para a polícia militar quanto a polícia civil, é justamente o CDP (Entrevista com morador, membro do Conseg, 2010).

Das cinco viaturas que nós temos, uma é para o município com 14 mil habitantes e quatro para 4 mil presos. Hoje as solicitaçôes para escoltas são constantes durante toda a semana e o contingente hoje está se refletindo em fazer escoltas (Entrevista com policial militar, 2010).

Já os conflitos de ordem moral são explicitados nas relações entre moradores e familiares de presos, cujo impacto é refletido na criação de novas categorias de outsiders vinculadas com a delinquência, diretamente atribuída aos familiares dos presos.

No comércio eu acho que atrapalha bastante por causa das visitas de presos. O que atrapalha nós é a visita. Se eu trabalho, vamos supor, com uma pessoa só durante a semana, chega de sexta, sábado, eu tenho que ter no mínimo duas ou três. Você acaba vendendo mais aos finais de semana, mas ao mesmo tempo... Ao mesmo tempo você tem que ficar com aquele cuidado, né? Você não sabe se elas entram pra mexer, se elas entram pra roubar... (Entrevista com comerciante, 2008).

As pessoas da cidade evitam até encostar na gente, parece que a gente vai contaminar elas, porque elas olham pra gente e sabe que a gente é de fora (Entrevista com esposa de um preso, 2010).

No que diz respeito aos agentes penitenciários, mesmo considerando que a família das pessoas presas tenha um papel significativo no processo de ressocialização dos encarcerados, eles constantemente tecem críticas às 
mulheres que visitam seus parceiros e avaliam que o trabalho nos finais de semana, ou seja, nos dias de visita, é exaustivo e desgastante por conta das revistas realizadas nos jumbos ${ }^{4}$ e da intensa movimentação de mulheres e crianças na unidade. Além disso, reproduzem as ideias dos comerciantes, relacionando essas mulheres a pessoas "moralmente" inferiores e potencialmente criminosas.

No município? Aí eu já não tenho como responder muito, só vejo as visitas na penitenciária. Agora no cotidiano, na rua, não posso falar. Sabe-se que tem o sentido pejorativo sim, não saio pra rua à noite, então não posso falar muito, mas acredito que boa coisa não é, existe as meras exceções (Entrevista com agente penitenciário, 2010).

Olha, as visitas... A minha opinião particular é o seguinte: são todas mulheres carentes, em todos os sentidos, a sua maioria são pobres, grande parte delas já tem filhos com presos, algumas tem filho com um preso e hoje visitam outro. Então grande parte delas vem pra penitenciária, além do sexo, vem pra se alimentar, elas se alimentam no sábado e no domingo, os presos dão dinheiro pra elas pagarem as pensōes por aí. Existem presos que dão o dinheiro que elas gastam com os filhos, essa é a verdade. Eles [presos] não têm vínculo, porque o preso hoje aqui consegue, através de carta, de rádio, uma pessoa da rua pra ir visitá-lo, depois se ele é transferido lá pra Americana ele já arruma outra pessoa lá. Tanto que o Estado hoje está controlando, porque tinha preso que tinha cinco, seis mulheres, hoje pra você tirar uma e colocar outra, só depois de seis meses, porque senão vai chegar uma hora em que vai ter preso com cinco, seis filhos, cada um com uma mãe (Entrevista com agente penitenciário, 2010).

Durante uma reunião do Conseg, autoridades municipais e da administração prisional discutiram com os demais membros presentes possíveis "soluçôes" para a visibilidade de um prédio anexo de uma das penitenciárias que abrigava presos do regime semiaberto. Nesse prédio não há muros que o isolem da rua, apenas um alambrado de metal que possibilita a visualização entre os presos da ala e as pessoas que passam. Segundo a autoridade municipal presente, eram muitas as reclamaçōes recebidas por parte dos moradores. A discussão seguiu até que o diretor da unidade se comprometesse a angariar verbas estaduais para a construção de um muro em substituição ao alambrado e, em contrapartida, a autoridade municipal se comprometeu a realizar a limpeza do terreno ao lado do local, que, segundo a administração prisional, poderia facilitar a fuga dos detentos.

\footnotetext{
4. Jumbo é a categoria nativa usada para denominar as sacolas com mantimentos, produtos de higiene e outros pertences que as mulheres levam para seus parentes presos nas unidades prisionais. Em geral são sacolas grandes e de plástico transparente, por recomendação da administração da penitenciária, para facilitar a revista na entrada da unidade.
} 
5. Os termos que aparecem transcritos em itálico são nativos, encontrados na fala dos interlocutores da pesquisa.
É possível observar, a partir desses dados, que a presença de presos e seus familiares nessa pequena cidade do interior é considerada um "problema" que atinge diversas áreas e setores da administração municipal. Esse problema torna-se objeto de constante negociação entre administração municipal e prisional (que pertence à esfera estadual), que em várias oportunidades chegam a partilhar decisões de gestão do cotidiano prisional. Fica claro que a gestão prisional não se restringe ao intramuros da prisão, mas é levada a uma instância pública de debate, muitas vezes permeada por moralidades e valores que desconhecem tanto a rotina prisional como o sistema de justiça criminal.

Já no intramuros das prisões, as ações de compartilhamento configuram uma das principais estratégias para garantir que a administração dos presídios consiga tocar a cadeia ${ }^{5}$, ou seja, garantir um equilíbrio, mesmo tenso, que permita administrar o cotidiano sem que os conflitos entre guardas e presos tomem proporçôes de rebeliāo ou motim. Nos dizeres de um diretor de unidade prisional:

Pra manter a ordem é assim: a gente finge que tá no controle e os caras fazem o controle deles lá dentro. Só que o ladrão sabe que, se aprontar alguma, a gente vai com tudo lá pra cima deles (Entrevista com diretor de segurança e disciplina em unidade prisional do oeste paulista, 2005).

Atualmente, o principal marcador de diferenciação das relaçôes entre corpo diretivo e população prisional decorre da estratificação produzida pela existência dos diferentes coletivos de presos presentes nas cadeias paulistas. Segundo relatos de diretores de presídios, a cadeia do PCC, embora mantenha a tensão constante da iminência de atos de oposição ao Estado (cf. Biondi, 2010; Marques, 2009), torna-se mais facilmente administrada em decorrência da presença de lideranças locais:

Em cadeia do PCC a gente conversa com um, dois caras, e resolve como a cadeia anda. Antes não, a gente negociava no varejo, conversava com um monte de gente e mesmo assim sempre tinha confusão, porque ninguém mandava na cadeia e todo mundo queria ser fodão (Entrevista com diretor de unidade prisional que em 2008 passou por mudança de perfil da sua população, deixando de ser cadeia neutra - aquelas em que os presos não pertencem a nenhum coletivo - e recebendo presos tidos como ligados ao PCC).

Dessa forma, o cotidiano é marcado por regras de convivio não estabelecidas oficialmente, mas que permitem aos diretores evitar conflitos 
que ultrapassem os limites das muralhas. Embora o discurso público da administração penitenciária busque reforçar as estratégias de controle, segurança e disciplina, o que se observa no interior das unidades prisionais são variaçôes entre estratégias de força estatal e ações de negociação entre a administração e os presos.

No plano político, na gestão dos conflitos há uma subordinação dos atores estatais locais às políticas estaduais, que não são receptivas às demandas locais e tampouco as reconhecem. Além disso, as políticas judiciais priorizam o encarceramento como a principal punição para os crimes patrimoniais e de drogas, focalizados ainda em uma camada social específica. Assim, as políticas estaduais investem na estrutura do sistema prisional ampliando-o significativamente, ao passo que as políticas judiciais não buscam medidas alternativas à prisão, gerando um processo crescente de encarceramento em massa e direcionado.

É curioso notar que, embora os familiares de presos sejam reconhecidos no discurso institucional como parceiros importantes nas açôes de ressocialização e no cuidado com os presos (garantindo inúmeras vezes as condiçôes mínimas de higiene e alimentação), são ao mesmo tempo vistos como suspeitos. Tanto as pessoas que convivem com o cotidiano prisional do lado de fora das prisóes quanto os agentes, internamente, associam a imagem dos familiares a potenciais criminosos que estão ali à espera de uma "oportunidade" para cometer um crime.

A partilha do "tratamento penitenciário": o caso do monitor preso de educação

Oriundo das concepções consolidadas nas "Regras Mínimas para o Tratamento dos Reclusos", aprovadas em 1955 pelo Conselho de Defesa Social e Econômica da Organização das Nações Unidas (ONU), o conceito de "tratamento penitenciário" refere-se a

[...] um conjunto articulado de açôes por parte do Estado e da sociedade, para a garantia de direitos fundamentais básicos (como o direito à sobrevivência, o direito ao desenvolvimento pessoal e social, além do direito à integridade física, psicológica e moral) por meio de políticas sociais básicas (saúde, trabalho e educação), políticas de assistência social, políticas de proteção especial e políticas de garantia de direitos (Julião, 2010, p. 537). 
6. Resolução n. 3 de 2009, do Conselho Nacional de Política Criminal e Penitenciária, e Resolução n. 2 de 2010, do Conselho Nacional de Educação.
Essas ações devem, segundo uma ótica normativa, promover a "reintegração social" das pessoas encarceradas, prevenindo sua "reincidência". Como afirma Julião, para os diferentes agentes operadores da execução penal (membros dos sistemas de justiça e da administração penitenciária) a reintegração social corresponde ao indivíduo "'voltar à sociedade adaptado, respeitando as leis'. Ou seja, 'o preso deve voltar para a sociedade sem delinquir" (Idem, ibidem).

Em que pese o investimento estatal voltado majoritariamente para a expansão de vagas e construção de novas unidades prisionais, ações de incentivo ao "tratamento penitenciário" ocorrem concomitantemente a essa expansão. Exemplo disso foi o movimento iniciado pelo governo brasileiro em 2005, numa ação liderada conjuntamente pelo Ministério da Justiça e o Ministério da Educação com o intuito de estabelecer uma política nacional, pactuada com os entes federativos, de promoção do acesso e da qualidade de oferta de educação nos estabelecimentos penais. Tal política deveria constituir um dos eixos centrais para a melhoria do "tratamento penitenciário" nos estabelecimentos penais brasileiros e, para tanto, deveria ser resultante de um amplo processo de diálogo e articulação entre governo federal, governos estaduais e organizações da sociedade civil.

A partir de então foram realizados dois seminários nacionais $(2005$ e 2006), encontros regionais, fóruns de debates e audiências públicas, além do financiamento de projetos experimentais executados em alguns estados. Todo esse movimento deu origem a duas normas regulamentares ${ }^{6}$. Ambas têm como propósito a institucionalização de parâmetros para a oferta de educação nas prisões. Entre esses parâmetros, a transferência da responsabilidade por essa oferta para as secretarias estaduais de educação e a necessidade de dotar os sistemas de ensino na prisão de profissionais do quadro do magistério.

Seguindo trajetória distinta a esse movimento, o estado de São Paulo, por intermédio da Funap - Fundação Prof. Dr. Manoel Pedro Pimentel, iniciou em 2004 a implantação de um programa de educação que assumia como elemento central de execução das atividades pedagógicas o monitor preso de educação. Tal proposta remonta a experiências surgidas durante o regime militar, em que presos políticos ministravam aulas para colegas de cela com menor escolarização. Porém, a partir de 2004, a Funap assumiu essa proposta como estratégia político-institucional, considerando o monitor preso como sujeito privilegiado de mobilização da comunidade escolar no interior das unidades prisionais e como agente específico de construção 
de conhecimentos significativos para essa comunidade de alunos, não restringindo o conhecimento aos conteúdos escolares tradicionais (cf. Melo e Prado, 2010; Melo e Oliveira, 2010).

Segundo o projeto político-pedagógico da fundação, levado a cabo no período de 2004 a 2012, “o monitor preso tem o papel de articulador e representante entre o sistema educacional e o grupo em que está inserido. É a pessoa que irradia a educação na massa carcerária e demonstra a valorização da educação" (Funap, 2010, p. 30).

A proposta foi objeto de diversas críticas entre educadores e pesquisadores do campo da pedagogia, desde aquelas menos fundamentadas, que enxergam apenas uma suposta "política de redução de gastos" (Cunha, 2010, p. 170), passando por posiçóes corporativistas que apontam para a necessidade da ação exclusiva de "profissionais habilitados e concursados" (Da Silva, 2010, p. 29) - argumentos ingênuos que caracterizam a posição do monitor preso como "motivo de preocupação, pois se torna um cargo de visibilidade, de destaque e de liderança, o que pode resultar em confronto entre os presos" (Carreira, 2009, p. 63) -, até relatos de situaçôes frustrantes vividas por presos e presas que frequentam ou frequentaram escolas em unidades prisionais paulistas (cf. C. R., 2010, pp. 48-51).

Não obstante o debate pedagógico em torno disso, o que se observou no período relatado foi a identificação de que tais presos passaram a ocupar uma posição diferencial na relação entre ladrôes $^{7}$ :

Desde 2004 as Penitenciárias I e II de M... haviam aderido ao novo programa de educação da Funap e, em 2006, contávamos com um grupo de educadores já bastante afinados com a proposta pedagógica difundida pela Fundação. Em certa ocasião, ao visitar a Penitenciária I para reunir-me com os monitores presos, notei que havia nas costas de seus uniformes a inscrição "professor". Questionando-os quanto àquela diferenciação, tomei conhecimento de que ela partira da própria rapaziada, e fora autorizada pela diretoria da unidade. É pra marcar nossa responsa, disse-me o monitor preso Washington (Melo, 2006-2012).

Percebe-se que o exercício de uma função "profissional", ligada a um programa institucional, permitiu a construção de uma nova posição nas relaçóes entre ladrôes, por meio da qual se desenrolam novos jogos de poder e novas manifestações de controle e dominação.

Se, no projeto mencionado, o monitor preso é compreendido pela Funap como o sujeito de articulação entre o espaço escolar e os demais espaços da
7. Ladrōes é categoria nativa enunciada para sinalizar posiçôes econômicas, morais e políticas ocupadas por indivíduos que compartilham atitudes, valores, condutas e procedimentos no interior do mundo do crime. É construída em oposição tanto aos criminosos sexuais, aos consumidores contumazes de drogas, quanto aos policiais e agentes estatais da ordem. 
dinâmica prisional, para dirigentes de unidades prisionais surgem representações distintas:

O monitor preso é bom porque evita a entrada de gente de fora na prisão. Além disso, ele aumenta o rateio, que é importante pras unidades aqui da região. Mas a gente tem que tomar cuidado, tem que monitorar, que vigiar os caras o tempo todo, senão eles aprontam. Muito preso vai pra sala de aula só pra conversar, pra fazer esquema, e o monitor preso não tem força pra apontar os erros (Entrevista com diretor geral de unidade prisional. Melo, 2006-2012).

Eu fui um dos que mais resistiram ao monitor preso. Pode perguntar aí, todo mundo sabe que minha unidade foi a última a aceitar o monitor preso. Hoje eu mudei minha visão. Os monitores fazem um ótimo trabalho, se dedicam, e levam a sério o papel de professor. Antigamente a gente não via a qualidade que a gente vê hoje nas aulas (Entrevista com diretor da área de trabalho e educação em unidade prisional. Melo, 2006-2012).

Perguntados se, na visão deles, havia algo que distinguia os monitores presos do restante da população prisional, um diretor aceitou se manifestar:

8. Trata-se, como descreve Marques (2009), de um complexo conjunto de regras que organiza a experiência cotidiana da vida na prisão, implicando em divisões de ordem moral e espacial e na distribuição de presos e presas por diferentes coletivos.
$\mathrm{Ah}$, isso existe. $\mathrm{O}$ monitor preso tem de ter um comportamento, não pode se meter em confusão, não pode se meter em drogas e nem ter dívida dentro da cadeia. Se o cara não se garantir, ele é tirado fora. [...] Os caras são cobrados lá dentro e são cobrados pela diretoria também. Então tem que ter uma responsabilidade, senão o cara não aguenta (Entrevista com diretor da área de trabalho e educação em unidade prisional, 2011. Melo, 2006-2012).

Depreende-se de tal declaração que para o monitor é permanente a necessidade de se afirmar perante a rapaziada - se garantir! - e a exigência da rapaziada de que os professores garantam o seu proceder $^{8}$, não se envolvendo com o consumo de drogas ou dívidas.

Não há unanimidade em relação à aceitação, pelos dirigentes de unidades prisionais e agentes de segurança penitenciária, da institucionalização do monitor preso de educação no Programa de Educação da Funap. Segundo um diretor de penitenciária na região de Sorocaba:

O monitor preso não consegue prender o aluno em sala de aula, não consegue [...] ele não impõe o mesmo respeito [que um professor externo]. Tem que ter um 
funcionário junto, porque ele não consegue ter um comando sobre a turma. Se o guarda não estiver ali, eles não vão respeitar o professor (Entrevista com diretor geral de unidade prisional. Melo, 2006-2012).

Já um dirigente na região de Ribeirão Preto, afirma ser

[...] totalmente favorável ao monitor preso. Nós temos referências negativas de sobra para dizer quem é o preso: é piloto, é faxina, é exu. O monitor preso é o maior referencial positivo que existe dos presos: ele tem compromisso, horário, salário (Entrevista com diretor geral de unidade prisional na região de Ribeirão Preto, 2011. Melo, 2006-2012).

A diferenciação manifestada pelos diretores condensa elementos representativos das contradições implícitas na prisão. Ora expressando as preocupações proeminentes de segurança e disciplina, ora destacando as contribuições para ações de "ressocialização" dos presos, sobressai dos relatos a necessidade de distinção entre o professor preso e a massa carcerária. Tal distinção é realçada em depoimentos de monitores presos:

No raio9 onde me encontro e até mesmo nos outros raios sinto que mesmo agindo como reeducando as pessoas ainda me tratam como professor. Exemplo: chamam-me por professor, fazem perguntas com relação à escola, perguntam sobre meio ambiente e ainda me convidam para participar de alguns eventos onde me tratam como professor e algumas pessoas, ainda que inocentemente, fazem perguntas sobre a minha situação processual (Entrevista com Da Costa, monitor de Ensino Fundamental em unidade prisional na região noroeste paulista, 2011. Melo, 2006-2012).

Apontando para outro sentido de diferenciação, alguns deles indicam no exercício da função a oportunidade de construir novas trajetórias de vida:

O monitor pode fazer a diferença, e a diferença pode ser feita de uma forma voluntária e informal, pois pode fazer os companheiros entender que cada um de nós pode mudar esta trajetória e darmos uma nova direção em nossas vidas. E se envolver neste trabalho requer dedicação e percepção para lidar com um cotidiano cheio de sentimentos e em conflito constante (Entrevista com Barbosa, monitor de sala de leitura em unidade prisional na região noroeste paulista, 2011. Melo, 2006-2012).
9. Raio designa a divisão dos pavilhôes habitacionais, como será explicado adiante. 
O que se destaca nos depoimentos e nas relações observadas em campo é que este ator incorpora três facetas de diferenciação. Para a Funap, tratava-se de uma posição-chave na execução de seu programa de educação. Para diretores e demais funcionários das unidades prisionais, são presos com acesso a dinâmicas distintas da rotina da administração, não estando submetidos aos mesmos padróes de horários e trânsito que os demais presos de cada unidade. Para a população prisional, são os professores, tendo de se equilibrar entre um comportamento que legitime essa diferenciação e permita a ele ser aceito e visto como tal, e um proceder que não o distancie do mundo do crime, de modo a permanecer no convívio com seus companheiros.

Ao incorporar a posição do monitor preso de educação como figura-chave de execução de um programa institucional, evidencia-se não apenas o compartilhamento da gestão do cotidiano, mas também as formas como tal compartilhamento representa o convívio, conflituoso e precário, entre as estratégias de promoção do "tratamento penitenciário" e o incremento das ações de controle e vigilância. Assim, conquanto possa ser vista como uma posição residual, cuja permanência ou, ao contrário, o desaparecimento possam se dar em função de políticas temporárias, o que o monitor preso informa é a existência, sempre presente, de elos relacionais entre um discurso estatal e práticas extraoficiais que assegurem a produção e a reprodução do sistema prisional.

\section{Entre o tratamento penitenciário e o controle dos corpos}

Conforme descrito, a gestão do cotidiano nas unidades prisionais desdobra-se por meio de negociações constantes entre a administração oficial e as posições estratégicas forjadas no convívio entre os presos e entre estes e os operadores do próprio sistema. O equilíbrio precário nessas negociaçóes se manifesta ainda no conflito também constante entre as ações de "tratamento penitenciário" e de controle da população prisional. Dinâmicas relacionadas com a forma de ocupação dessas unidades, a distribuição espacial dos presos e seu trânsito interno pelos diferentes setores das prisóes geram formas es-

10. Dados disponíveis em <http://noticias.terra.com.br/ brasil/noticias/0,,OI5624192-EI5030,00-Jornal+deficit+no+s istema+prisional+passa+de+mil+ vagas+em+SP.html>, consultado em fevereiro de 2012 . pecíficas de organização das atividades promovidas pelo Estado, com forte proeminência dos mecanismos de contenção.

Tome-se, para ilustrar, a ocupação das unidades prisionais e a distribuiçãoo dos atendimentos de "tratamento penitenciário".

No início de 2012, o estado de São Paulo apresentava um déficit de cerca de 84 mil vagas no sistema prisional ${ }^{10}$. Mesmo num contexto de superlo- 
tação, as ações educacionais realizadas nos presídios abrangem em média 16 mil alunos por mês. Os postos de trabalho envolvem cerca de 30\% da população total. É constante a disputa entre a educação e o trabalho pela ocupação do tempo de cada indivíduo preso e, no geral, o dia útil nas prisões não é superior a seis horas, período em que os presos se dividem entre trabalhar, estudar, receber atendimentos jurídico, social, psicológico, médico etc. Ao contrário do que afirma o senso comum, o que se depreende dessa rotina é que "preso não tem tempo de sobra".

As rotinas da prisão giram em torno da "segurança" e da "disciplina" Segurança, supostamente, para os guardas e para a população externa às muralhas; disciplina para os corpos que deveriam ser "adestrados" 12 . O corpo funcional da administração penitenciária é formado na maioria por agentes de segurança penitenciária (ASPs) e agentes de escolta e vigilância penitenciária (AEVPS), sendo reduzidos os quadros de oficiais administrativos e técnicos das áreas de saúde e de reintegração social. Não há um número fixo de funcionários previamente determinado, e a cada novo estabelecimento prisional inaugurado edita-se um decreto específico no qual é definido o quantitativo de agentes de segurança, agentes de escolta e vigilância e demais profissionais de setores técnicos e administrativos. No entanto, a predominância é sempre de funcionários de "segurança”.

A rotina de atividades é controlada a partir dos horários de tranca. $\mathrm{Na}$ maior parte das unidades, dá-se a soltura diária por volta das 7 h30 da manhã, horário em que os presos que trabalham ou estudam são liberados para as oficinas ou escolas, respectivamente. Trata-se de um grupo reduzido, quando se considera o total de presos de cada estabelecimento.

Antes daquele horário, um grupo ainda mais reduzido já deixou as celas - o pessoal da cozinha, responsável pelo preparo da alimentação da rapaziada. Sobre ele incide um processo rígido de seleção e vigilância por parte da população prisional, uma vez que se trata de um grupo com possibilidades diretas de interferência na vida de todos os demais presos ${ }^{13}$. Por isso, ser da cozinha reflete o respeito conquistado ao longo de uma caminhada.

Entre as $7 \mathrm{~h} 30$ e as $10 \mathrm{~h} 30$ se desenrolam as atividades matutinas da prisão, que voltam a ser interrompidas por nova tranca: em torno das $11 \mathrm{~h}$, a maior parte dos presos já se encontra recolhida nos pavilhões habitacionais, onde será servido o almoço.

A tranca reabre às $13 \mathrm{~h}$, quando se inicia o período de atividades da tarde, que se estenderá, quando muito, até as 16h. Após esse horário, retorno ao
11. A administração de cada unidade é composta pela diretoria geral e diretorias de áreas, e nestas há variaçôes entre os diferentes modelos de unidades e regimes. No geral, entretanto, a Diretoria do Centro de Segurança e Disciplina é, abaixo da diretoria geral, a mais importante na tomada de decisões e na definição de procedimentos internos de cada estabelecimento. O que observamos em diversas unidades é que dificilmente diretores gerais e de segurança participam de eventos externos ou reuniōes ao mesmo tempo, sendo sempre necessária a presença de um dos dois na unidade prisional. Por outro lado, é comum que, na ausência do diretor geral, a responsabilidade pela administração do estabelecimento seja transferida para o diretor de disciplina. É também esse diretor que, na maior parte das unidades, estabelece as rotinas das demais áreas - educação, trabalho, atendimentos técnicos -, submetendo-as aos seus critérios de importância.

12. O estatuto da Funap preserva até hoje sua função social de "adestrar os presos".

13. Dirigido por Marcos Jorge e lançado em 2009 pela Europa Filmes, o filme "Estômago" recebeu dezenas de prêmios nacionais e internacionais ao retratar a trajetória ascendente de Raimundo Nonato no universo da culinária e das relações de poder que se desenrolam numa prisão. Inserido 
nessas relaçōes, Nonato utiliza seus conhecimentos culinários para conquistar a confiança das lideranças do presídio, culminando com sua chegada ao alto posto das relações entre ladrōes a partir do envenenamento de seu principal adversário.

14. Os dados referentes aos números de vagas estâo disponíveis em <www.sap.sp.gov.br>, consultado em abril de 2011. pavilhão habitacional, contagem, cela. As luzes serão apagadas por volta das $21 \mathrm{~h}$.

Dessa forma, em que pese o discurso de promoção da "reintegração social", o que se percebe é a pouca oferta de vagas e horários para que a população prisional esteja envolvida nas ações de "tratamento penitenciário".

Outro aspecto que influencia essas ações são as estruturas físicas das unidades prisionais. Em termos arquitetônicos, há seis modelos principais de estabelecimentos penitenciários, existindo ainda unidades com modelos diferenciados, em decorrência de seus períodos históricos de construção ou dos regimes de detenção que abrigam. A diversidade arquitetônica exerce influência direta nas relações entre ladrões, e entre estes e a administração das unidades. Tome-se o exemplo das penitenciárias compactas, modelo mais comum atualmente encontrado.

Trata-se de uma unidade dotada de oito pavilhões habitacionais, com capacidade para $768^{14}$ presos. Essas unidades são atravessadas por uma galeria central - chamada radial-com acessos laterais aos raios e aos pavilhões de trabalho, escola e cozinha. Como o nome já indica, são unidades em que os espaços - celas, áreas de convívio dos raios, pavilhões de trabalho, prédio administrativo etc. - são compactos. As celas distribuem-se num raio retangular, sendo o espaço central utilizado como quadra de esportes e área para outras atividades diversas. Um pavilhão originalmente concebido para oficinas de trabalho é utilizado para montagem das salas de aula.

Dividida em oito raios, a unidade conta, necessariamente, com oito faxinas. Como, na maior parte dos casos, são esses os presos que realizam a comunicação entre a rapaziada e os guardas, não é raro que uma mesma informação seja transmitida de forma diferente em cada pavilhão. A funcionária de uma unidade com essa arquitetura exemplifica as dificuldades geradas pelo modelo:

Eu estava com problema de matrícula de alunos na escola, com a adesão muito baixa para as turmas de alfabetização. Então chamei os postos culturais dos oito raios pra conversar, pois eu sempre digo que eles são o braço da escola dentro dos raios. Durante nossa conversa, um deles me interrompeu: "Ô dona A., a gente tá com um problema sério lá dentro. É que o seu Al. não faz assim como a senhora, que chama todo mundo junto e a gente acerta o que fazer. Quando ele quer acertar alguma coisa pra cadeia andar, ele chama um faxina de cada vez e aí ele conversa uma coisa com cada um. Então a gente nunca sabe o que pode combinar com ele, porque ninguém vai combinar uma coisa contrária ao que o companheiro 
combinou. Então a gente só concorda com o seu Al. e ele acaba fazendo tudo do jeito dele. Aí quando um faxina fala com o cultural do seu raio, e o cultural fala com o cultural do outro raio, a gente fica sabendo que o seu Al. combinou uma coisa diferente com cada raio e aí a gente fica sem poder fazer muita coisa”. Eu fiquei sem opção, porque como eu ia pedir ajuda pra levar gente pra escola, se os caras estavam ali justamente se sentindo enganados pelo meu diretor? (Entrevista, fevereiro de 2012. Melo, 2006-2012).

A localização da escola nesse modelo impõe restrições de acesso, uma vez que o trânsito interno de presos entre o pavilhão habitacional e os espaços onde ocorrem as demais atividades é sempre motivo de preocupação para os guardas, de modo que as diretorias de segurança e disciplina consomem boa parte de seu tempo em criar estratégias para diminuir esse trânsito.

No caso das atividades educacionais, não é incomum que os diretores desloquem todos os presos que vão à escola, bem como os monitores de educação, para um mesmo raio. A estratégia possibilita à diretoria de disciplina maior controle sobre quem sai dos raios para a escola e permite aos agentes de segurança uma rotina menos laboriosa de abertura, contagem, tranca e trânsito dos presos entre o raio e o pavilhão escolar.

$\mathrm{Na}$ unidade citada, porém, os alunos estavam distribuídos por todos os raios e, nesse caso, as dificuldades eram geradas por uma prática administrativa de tratar diferencialmente em cada raio as regras de trânsito pela unidade. Como consequência, instaura-se uma dinâmica de convivência entre os presos que é oposta ao próprio discurso da "reintegração social", uma vez que "ir à escola" se impõe como uma restrição a mais no convívio da prisão.

Observa-se a partir dos dados relatados que a gestão da vida na prisão e mesmo aquilo que pode ser considerado como tarefas do tratamento penitenciário - manutenção de vínculos familiares, projetos de reinserção social pelo trabalho, políticas destinadas à educação dos presos - são constantemente compartilhadas e negociadas entre instâncias da administração penitenciária, os grupos mais e menos organizados de presos e seus familiares. Os dados empíricos demonstram que no cotidiano das prisões existe muito mais do que uma aplicação imediata das diretrizes das políticas penais e penitenciárias. Assim, as dinâmicas sociais em torno das prisões são resultado de conflitos entre vetores em disputa dentro de um campo de forças em que Estado e mundo do crime se produzem constantemente e em relação. 


\section{Perspectivas analíticas}

Nos últimos anos, a produção que trata de punição e prisões conheceu um incremento importante, sobretudo com estudos realizados no estado de São Paulo, procurando registrar e compreender as mudanças do contexto.

Uma das constataçôes mais importantes dessa jovem produção são os traços obsoletos de pesquisas clássicas realizadas na Europa e nos Estados Unidos há vinte ou quarenta anos. Autores como Goffman (1974) e Sykes (1974) são referências ainda presentes, por terem construído categorias de análise que, aqui e agora, servem menos para ilustrar a realidade do que para pensar a diferença do presente em relação ao que foi discutido nas últimas décadas. Não que se tenha abandonado a leitura de Manicômios, prisóes e conventos ou de $A$ sociedade dos cativos. Parece que agora não se procura representar o caso brasileiro - o paulista em particular - como uma exemplificação das já descritas dinâmicas internas da vida nas prisões, mas estabelecer um diálogo crítico com pesquisas realizadas em outros países e contextos, buscando nos estudos clássicos categorias que possam servir de elementos de comparação por diferença com uma realidade empírica em larga transformação.

Dadas as especificidades de contexto e processo, é necessário manter o espírito crítico em relação a autores consagrados no debate atual, como é o caso de Loïc Wacquant ou David Garland. Não se pode reproduzir uma aplicação acrítica das categorias como "welfarismo penal" ou "estado penal", como se elas tivessem realidade empírica em qualquer tempo ou lugar, pois vivemos agora num mundo global em que as ideias circulam e onde todos estão submetidos às mesmas diretrizes dos organismos internacionais. Nada mais falso do que supor homogeneidade.

O próprio Wacquant (2001) achou necessário frisá-lo no prefácio de uma coletânea de artigos seus versando sobre estudos nos Estados Unidos e na França, publicada no Brasil: uma favela brasileira não tem a mesma configuração de um gueto norte-americano que, por sua vez, não constitui a mesma realidade do banlieu francês ou de uma villa argentina. E cada uma dessas formas sociais complexas - continua - insere-se num tipo de relação com políticas públicas, taxas de encarceramento, discricionariedade policial, formas de segregação e integração de grupos marginalizados que são distintas, constituindo arranjos históricos peculiares. E conclui que a comparação é mais útil para a compreensão do mundo contemporâneo quando faz ressaltar as diferenças do que quando aponta para semelhanças. 
O mesmo esforço está presente na reflexão de David Garland (2008) sobre o encarceramento em massa. Observar o crescimento do número de prisões em uma quantidade significativa de países não pode ser idêntico a supor que todo aumento da taxa de encarceramento possa ser explicado pelas mesmas causas e que vá gerar as mesmas consequências em todos os países. E, ao seguir essa recomendação metodológica, é válido ressaltar que o encarceramento em massa que se assiste em São Paulo não é uma realidade para todo o Brasil. Em nenhum outro estado brasileiro o número de prisões avançou tão rapidamente e nenhum estado construiu penitenciárias na intensidade em que vemos localmente. Da mesma forma, as políticas penitenciárias e penais ou de segurança pública não são semelhantes nem mesmo nos estados vizinhos. E a expansão dos negócios do PCC para além da fronteira física paulista não parece estar produzindo - ainda sabemos pouco sobre isso - os mesmos efeitos em termos de gestão econômica ou moral da relação entre parceiros ou com adversários ${ }^{15}$.

No diálogo que vimos estabelecendo com essa produção recente, a partir da interpretação de nossos dados empíricos, vemos a circulação de duas grandes teses sobre a especificidade paulista, que são de certo modo construídas e compartilhadas por vários autores que emergiram no debate recente. De um lado, há um enfoque nas políticas estatais e, de outro, na organização dos presos e nas relações no interior do mundo do crime. Poucos são os estudos que relacionam esses atores e forças no interior de um campo de lutas, dos quais destacamos a abordagem de Camila Dias (2011).

Quanto aos autores que focalizam a análise do Estado, têm prevalecido estudos com objetivos normativos, preocupados em documentar arbitrariedades e violações às normas jurídicas nacionais. Tem-se refletido sobre o significado da adoção de institutos normativos como o RDD ou a criação de condições excepcionais de custódia. São pesquisas que revelam engajamento com a crítica ao encarceramento em massa e às políticas de gestão penitenciária, porém seu potencial de explicar as novidades surgidas no campo é pequeno, já que não se tem notícia de estudos sobre prisões no Brasil em que a violência e as arbitrariedades da administração prisional não estejam presentes (cf. Horta, 2012; Koerner, 2001; Ramalho, 1979). Apenas reiterar a persistência da violência estrutural é pouco útil para explicar o que move os atores estatais na direção de quadruplicar o sistema penitenciário em pouco mais de uma década e modificar a normatividade jurídica que rege sua atuação contemporânea.

Como explicar que um Estado que tradicionalmente tolerou o arbítrio e a violência no interior do sistema penitenciário (cf. Horta, 2012) e que
15. Ainda se sabe pouco, mas a pesquisa de Lourenço e Almeida (2012) aponta indícios de aumento dos homicídios e da violência no interior das prisōes em Salvador, concomitante à identificação de parceiros do PCC atuando em território baiano. A pesquisa de Márcio Bonesso investiga presentemente os efeitos da expansão do PCC na gestão do tráfico de drogas em cidades do Triângulo Mineiro, onde parece que a presença dos "paulistas" provoca diferenciação e temor, mais do que identificação e confiança popular em seus métodos de administração de conflitos achados diversos do que tem sido retratado em relação às periferias paulistas. 
sempre conheceu as normas informais que regeram o cárcere (cf. Ramalho, 1979; Coelho, 1987) passasse, em dado momento, a valorizar a norma jurídica e se engajasse em disputas para alterar o conteúdo das normativas nacionais em vigor (cf. Teixeira, 2010)? Não se pode entender isso olhando o Estado como homogêneo ou filtrando as disputas de grupos de poder ou de projetos políticos diversos.

Na pista de observar a atuação estatal a partir do enfoque normativo, tem-se dado menos relevância ao questionamento da efetividade e até da eficácia das políticas penais para determinar o que é gestado no cotidiano da vida no interior das prisões. Preocupada em acompanhar o que se produz como documentos oficiais e discursos conduzidos no espaço público - que certamente criam efeitos de poder e constituem balizas no interior de um campo de lutas -, Teixeira (2010) deixa de considerar aquilo que Dias (2011) põe em relevo quando constata, na gestão cotidiana da política penitenciária, que as leis e normas jurídicas funcionam menos para serem aplicadas do que para produzirem mecanismos de negociação informal entre a administração local da prisão e as lideranças políticas de presidiários.

O caráter arbitrário da gestão penitenciária existia no passado, como existe no presente. Contudo, procuramos aqui demonstrar a presença de conflitos de projeto no interior do Estado, conflitos entre instâncias governamentais que interferem na gestão prisional ou que simplesmente administram as consequências do encarceramento em massa. Da administração desses conflitos surgem inclusive hierarquias entre instâncias governamentais, entre funções estatais, e recursos e autoridade são desigualmente distribuídos, gerando impacto sobre centenas de milhares de vidas dentro e fora dos presídios.

Do ponto de vista analítico, procuramos chamar a atenção para esses conflitos de projeto no interior do Estado, cuja homogeneidade e consistência só podem ser pensadas em termos típico-ideais, e não como realidade empírica (cf. Weber, 1991). Em decorrência, o caso empírico que analisamos mostra fissuras e conflitos na recepção e execução de ações e nos modos de pensar marcados pelas tendências hegemônicas de ampliação do encarceramento e de endurecimento penal. A necessidade funcional de compartilhar com os presos e com seus familiares as tarefas da gestão do cotidiano, a segurança no interior das prisões e as açóes caracterizadas como de ressocialização coloca constantemente em xeque a capacidade estatal de determinar, por meio de normas, códigos e normativas técnicas, os objetivos e as consequências da prisionalização. 
Não obstante, o fato de esse compartilhamento ser informal e não ocorrer de forma pública em espaços de participação e igualdade de representação leva à criação de hierarquias e relações desiguais de proposição e força, seja entre os diferentes atores estatais que se ocupam da gestão do encarceramento, seja entre os grupos de presos, seja entre os familiares.

Este último aspecto tem sido tratado pelas análises que enfocam a emergência de um novo sujeito político (os grupos organizados de presos) com capacidade de negociar condições e relaçôes, de criar efeitos de poder a partir de sua ação, que também cria balizas no campo de lutas, limitando, confrontando e produzindo deslocamentos na capacidade de efetivação das diretrizes legais ou das decisões dos gestores localizados na capital do estado.

Onde uns enxergam o encarceramento em massa produzindo destituição do sujeito de direitos, outros apontam os indícios da emergência de um novo sujeito político, de ações coletivas que produzem identidades e impactam profundamente a gestão penitenciária a partir da emergência de posiçôes políticas ocupadas de forma organizada e de um projeto comum. A emergência desse sujeito político, como nos esforçamos em documentar, produz deslocamentos e transformações, ocupa espaços, produz significados, marca presença, mas está longe de apontar para uma realidade homogênea: nem todas as companheiras de presidiários se orientam pelos mesmos princípios e horizontes de futuro, as trajetórias de egressos não apontam para comunidades de destino, a emergência de novas identidades e formas de intervir sobre a vida na prisão não estão necessariamente aprisionadas à política do cotidiano predominante no convívio das penitenciárias. A política estadual de educação nas prisōes criou a posição do monitor, que foi ocupada e ressignificada pelos presos com a figura do professor, mais um mediador das relaçôes políticas que organizam a gestão da vida nas prisões.

Por outro lado, os estudos que identificam a aparição de grupos de prisioneiros com a emergência de um novo sujeito político (cf. Biondi, 2010; Marques, 2009), cuja ação veio alterar o equilíbrio de forças da gestão cotidiana de repressão, vigilância, disciplina e violência nos cárceres, como nos espaços sociais em que seus efeitos se deixam sentir (cf. Feltran, 2011; Hirata, 2010), não valorizaram tanto a evidência de que, sob o novo regime moral que vige nas cadeias do $P C C$, há a invocação da instituição disciplinar, mais do que o seu questionamento ou a sua confrontação. A disposição discursiva de "guerra à polícia", de "virar cadeia", de confrontar constantemente a administração penitenciária, está curiosamente articulada à gestão da vida prisional por meio dos dispositivos de segurança e disciplina informais que 
16. Horta (2012) descreve em seu estudo sobre o presídio da Ilha Anchieta um tipo de exercício de poder apropriado pelos agentes mais capilares do sistema penal. E aquele parece ser um tipo de gestão do poder estatal no interior das cadeias bem diferente do praticado a partir dos anos de 1980, quando se passou à invocação de uma gestão profissionalizada ou técnica, com objetivos de ressocialização ou humanização, ou ainda de endurecimento do tratamento. permitem que "as cadeias andem", que "possam ser tocadas". Imagina-se que sem essa funcionalidade da "paz entre ladrôes" teria sido muito mais difícil expandir o sistema carcerário, inaugurar novas unidades prisionais e quadruplicar o número de presos.

Em vez da tese do "vazio do Estado" - cujo abandono em relação às prisões, governadas mediante violência e arbitrariedade, teria dado espaço ao surgimento da organização dos presos -, constatamos a ocorrência da expansão e do fortalecimento do poder estatal em sua função punitiva, no estado de São Paulo, tendo como indicadores não só o aumento quantitativo do número de presos, mas também as mudanças qualitativas na forma como instituições e atores estatais se relacionam com o encarceramento, as prisões e os presos.

O que parece ter ocorrido no advento dos anos de 1990, com o crescimento vertiginoso do encarceramento e a larga expansão das instalações penitenciárias, foi uma atualização das formas tradicionais de exercício do poder estatal nas prisões. Muito longe de um vazio, o que se vê é o estado paulista incrementando seu poder de punir, a partir da criação de novos presídios, de novos institutos e dispositivos, além de reapropriar-se de táticas de governo que há muito eram utilizadas ${ }^{16}$.

Esse incremento do poder estatal ocorreu simultaneamente a uma reorganização da gestão da vida por parte dos coletivos de presos. A simultaneidade precisa ser mais bem compreendida como uma relação entre elementos em disputa no interior de um campo de lutas. Mas esses elementos - administração prisional e grupos organizados de presos - não estão sempre só em confronto. Muitas vezes são vetores complementares que garantem a expansão da instituição disciplinar, com as peculiaridades de uma "disciplina à paulista".

Dito de outro modo, a intensificação do controle social repressivo centralizado, operado mediante as lutas internas dos agentes estatais ligados à gestão penitenciária, é tensionada constantemente pela oposição complementar de um controle social difuso, fundamentado nos dispositivos de segurança compartilhados entre os múltiplos agentes que participam da gestão da vida na prisão e interferem no seu espaço-tempo. O controle difuso se faz tanto por agentes e dispositivos institucionais como sob modalidades informais de gestão da vida, tendo sido reforçado - e não apenas combatido - pelas lutas de emergência do novo sujeito político, os coletivos de presos.

A convergência entre diferentes estratégias de controle social, exercidas de forma complementar entre atores e agentes políticos adversários num 
campo de lutas comum, é parte da explicação de um encarceramento em massa, que se mantém funcional e se expande continuamente por tanto tempo, sob tão poucos questionamentos.

\section{Referências Bibliográficas}

BIONDI, Karina. (2010), Junto e misturado: uma etnografia do PCC. São Paulo, Terceiro Nome.

CARreira, D. (2009), "Relatório Nacional para os direitos humanos à educação: educação nas prisões brasileiras". São Paulo, Plataforma DhESCA Brasil.

Coelho, Edmundo C. (1987), A oficina do Diabo: crise e conflitos no sistema penitenciário do Rio de Janeiro. Rio de Janeiro, Espaço e Tempo/Iuperj.

C. R. (2010), "Educação como direito humano: um olhar de dentro". In: YAMAMOTO, A. et al. Educação nas prisões. São Paulo, AlfaSol/Centro de Referência em Educação para Jovens e Adultos.

CunHA, E. (2010), "Ressocialização: o desafio da educação no sistema prisional feminino". Caderno Cedes, 30 (81): 157-178, maio/ago.

DA SiLva, D. A. (2010), "Responsabilidade sobre a educação nas prisões: Estado e sociedade civil". In: Yамамото, A. et al. Educação nas prisōes. São Paulo, AlfaSol/ Centro de Referência em Educação para Jovens e Adultos.

Departamento Penitenciário Nacional - Sistema de Informação Penitenciária - InfoPen. (2012), "Estatística”. Ministério da Justiça. Disponível em <http://portal.mj.gov.br/depen/data/Pages/MJD574E9CEITEMIDC37B2AE94C6840068B1624D28407509CPTBRNN.htm>, consultado em 1/9/2012.

DiAs, Camila. (2011), Da pulverização ao monopólio da violência: expansão e consolidação do Primeiro Comando da Capital (PCC) no sistema carcerário paulista. São Paulo, tese de doutorado em sociologia, Faculdade de Filosofia, Letras e Ciências Humanas da Universidade de São Paulo.

\& Silvestre, Giane. (2009), "Situação carcerária no estado de São Paulo". In: SouzA, L. A. F. (org.). Políticas de segurança pública no estado de São Paulo: situaçôes e perspectivas a partir das pesquisas do Observatório de Segurança Pública da Unesp. São Paulo, Cultura Acadêmica.

Feltran, Gabriel. (2011), Fronteiras de tensão: politica e violência nas periferias de São Paulo. São Paulo, Editora da Unesp/CEM.

Funap. (2010), Projeto politico-pedagógico. Arquivo pessoal.

GARLAND, David. (2008), A cultura do controle: crime e ordem social na sociedade contemporânea. Rio de Janeiro, Revan. 
Godor, Rafael. (2011), "Para uma reflexão sobre efeitos sociais do encarceramento". Revista Brasileira de Segurança Pública, 8: 138-154.

Goffman, Ervin. (1974), Manicômios, prisóes e conventos. São Paulo, Perspectiva.

Hirata, Daniel. (2010), Sobreviver na adversidade: entre o mercado e a vida. São Paulo, tese de doutorado em sociologia, Faculdade de Filosofia, Letras e Ciências Humanas da Universidade de São Paulo.

HORTA, Filipe M. (2012), “Ordenação, disciplina e punição militar: a ausência da vigilância e a presença de um suplício no Instituto Correcional da Ilha Anchieta (1942-1953)". Monografia de conclusão do bacharelado em ciências sociais. São Carlos, Centro de Educação e Ciências Humanas, Universidade Federal de São Carlos.

Juliẫ, E. F. (2010), "O impacto da educação e do trabalho como programas de reinserção social na política de execução penal no Rio de Janeiro". Revista Brasileira de Educação, 15 (45), set./dez.

Koerner, Andrei. (2001), “O impossível panóptico Tropical Escravista”. Revista Brasileira de Ciências Criminais, 35: 211-224.

LourenÇO, L. C. \& Almeida, O. L. (2012), "Gangues prisionais e dinâmicas violentas: poder e força dentro e fora do cárcere”. Trabalho apresentado no III Seminário de Estudos Prisionais, Controle e Violência. São Paulo, USP.

MARQUes, Adalton. (2009), Crime, proceder, convívio-seguro: um experimento antropológico a partir de relaçôes entre ladrões. São Paulo, dissertação de mestrado em antropologia social, Faculdade de Filosofia, Letras e Ciências Humanas da Universidade de São Paulo.

Melo, Felipe A. L de. (2006-2012), "Anotaçōes em caderno de campo". Arquivo do autor, não publicado.

. (2012), As prisões de São Paulo: dinâmicas, fluxos e as implicaçôes nas trajetórias de egressos prisionais. Uma perspectiva a partir do monitor preso de educação. São Carlos, dissertação de mestrado em sociologia, Centro de Educação e Ciências Humanas da Universidade Federal de São Carlos.

\& Oliveira, J. A. (2010), "Educação nas prisões: mais que reconhecer, é necessário efetivar esse direito com qualidade". In: ҮАмАмОтО, A. et al. Educação nas prisões. São Paulo, AlfaSol/Centro de Referência em Educação para Jovens e Adultos.

\& Prado, S. L. (2010), "Pode o preso dar aula? A experiência da educação de adultos nos presídios paulistas". Trabalho apresentado no I Congresso Internacional da Cátedra da Unesco de Educação de Jovens de Adultos. João Pessoa, PB, jul.

RAMALHO, José R. (1979), O mundo do crime: a ordem pelo avesso. Rio de Janeiro, Graal.

SALLA, Fernando. (2007), "De Montoro a Lembo: as políticas penitenciárias em São Paulo". Revista Brasileira de Segurança Pública, 1 (1). 
Silvestre, Giane. (2012), Dias de visita: uma sociologia da punição e das prisões. São Paulo, Alameda.

SYKES, Gresham M. (1974), The society of captives: a study of a maximum security prison. Princeton, Princeton University Press.

TeIXeIra, Alessandra. (2010), Prisóes da exceção: política penal e penitenciária no Brasil contemporâneo. São Paulo, Juruá.

Telles, Vera S. (2007), "Cidade e práticas urbanas: nas fronteiras incertas entre o ilegal, o informal e o ilícito”. Estudos Avançados, 21: 173-192.

WACQUANT, Loïc. (2001), Os condenados da cidade: estudo sobre marginalidade avançada. Rio de Janeiro, Revan/Fase.

. (2008), "O lugar da prisão na nova administração da pobreza”. Novos Estudos Cebrap, 80, mar.

Weber, Max. (1991), Ensaios sobre a teoria das ciências sociais. São Paulo, Moraes.

\section{Resumo}

Encarceramento em massa em São Paulo

A população prisional de São Paulo cresce acentuadamente. Mais de 30\% dos presos do país se distribui pelas 154 unidades prisionais paulistas. A política de descentralização das prisões e encarceramento em massa focaliza acusados por crimes patrimoniais e de drogas, jovens, homens e oriundos das periferias urbanas. O artigo aborda desdobramentos do encarceramento em massa, resultantes das normas e moralidades que regem a vida nas prisōes, sobretudo as formas de compartilhamento entre a administração e os internos e seus familiares na gestão do cotidiano na prisão. Tal compartilhamento ultrapassa os limites físicos das prisōes, produzindo efeitos sobre os mecanismos do encarceramento e o seu crescimento. Observou-se a negociação entre instâncias da administração penitenciária, os grupos organizados de presos e seus familiares para manter a ordem interna e para a execução das tarefas do tratamento penitenciário. A intensificação do controle social repressivo centralizado é tensionada pela oposição complementar de um controle social difuso, fundamentado nos dispositivos de segurança compartilhados entre os agentes que participam da gestão da vida na prisão. Palavras-chave: Prisōes; São Paulo; Punição; Educação nas prisōes; Controle social. 


\section{Abstract}

Mass incarceration in São Paulo

São Paulo's prison population has grown sharply. More than 30\% of the country's prisoners are found in the 154 prison establishments in the state. The policy of decentralizing prisons and mass incarceration focuses on people accused of property and drug-related crimes, typically young, male and living in urban peripheries. The article explores the repercussions of mass incarceration resulting from the norms and moralities governing prison life, especially the collaboration between prison administrations, inmates and their families in managing the daily life of the prison. This collaboration extends beyond the physical limits of the prisons, influencing the mechanisms determining incarceration and the increase in prison populations. The study observed negotiations between the administrations and organized groups of inmates and their families towards the shared goal of maintaining internal order to enable the work involved in penitentiary practices. The intensification of centralized forms of repressive social control is counterbalanced by the complementary opposition of a diffuse social control, grounded in the security procedures shared among the agents participating in the management of prison life. Keywords: Prisons; São Paulo; Punishment; Education in prisons; Social control.

Texto enviado em 10/1/2013 e aprovado em 24/1/2013.

Jacqueline Sinhoretto é professora do Departamento de Sociologia e do PPGS da UFSCar e líder do Grupo de Estudos sobre Violência e Administração de Conflitos

- Gevac-UFSCar. E-mail: <jacsin@uol.com.br>.

Giane Silvestre é doutoranda do PPG em sociologia da UFSCar e membro do Grupo de Estudos sobre Violência e Administração de Conflitos - Gevac-UFSCar E-mail: <silvestregiane@gmail. com>.

Felipe A. L. Melo é mestre em sociologia pela UFSCar e membro do Grupo de Estudos sobre Violência e Administração de Conflitos - Gevac-UFSCar. E-mail: <felipealmelo@yahoo.com.br>. 